\title{
Implementation of a bowel care protocol within intensive care
}

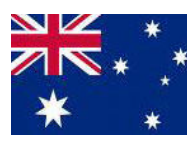

Michelle Ring RN; DIPHE (Adult), BSc Critical Care, Clinical Nurse, ICU, Mater Adult Hospital, South Brisbane, Australia

Key Words: bowel care constipation $*$ intensive care * protocol

E-mail: michelle.ring@mater.org.au

\section{ESPAÑOL}

Implementación de un protocolo de cuidado intestinal en cuidado intensivo

Palabras clave

Cuidado intestinal, constipación, cuidado intensivo, protocolo

Resumen

Nuestra UCl de tercer nivel con once camas no tenía un protocolo formal de cuidado intestinal implementado. El cuidado intestinal se manejaba administrando una variedad de laxantes. Nuestras observaciones en varios meses revelaron que la constipación era un problema.

Una pequeña auditoria se realizó en junio-julio de 2008 en siete pacientes. Todos los pacientes estuvieron intubados y ventilados, recibían alimentación enteral y no tenían cirugía intestinal.

Los objetivos fueron determinar cuánto tiempo después de la admisión los pacientes recibían laxantes, que laxantes recibían y cuánto tiempo después de la admisión el intestino del paciente recuperaba su función.

Los pacientes recibían laxantes al cuarto día después de la admisión en promedio. Todos los pacientes recibían jugo de ciruelas y luego una variedad de macrogol (Movicol ${ }^{\mathrm{TM}}$ ), lactulosa, enema (Microlax ${ }^{\mathrm{TM}}$ ), y senna. En promedio, el intestino recupero su función al día nueve después de la admisión. Se identificó la necesidad de un protocolo de cuidado intestinal, el protocolo se desarrolló entre junio y febrero de 2008.

Las sesiones educativas se realizaron a partir de Marzo 2009 en adelante, el protocolo fue implementado en Julio de 2009.

Se repitió una auditoria entre Mayo-Junio de 2010 en siete pacientes. El protocolo se inició en el primer o segundo día de admisión en promedio.

Los intestinos recuperaron su función en el día 5,3 después de la admisión, en promedio. Es claro por los resultados, que la implementación de un protocolo formal mejoró el cuidado intestinal y disminuyó la constipación.

\section{SUMMARY}

- Our eleven-bed level three ICU did not have a formal bowel care protocol in place. Bowel care was addressed by giving a variety of aperients. Our observations over a period of several months revealed that constipation was a problem.

- A small audit was carried out in June-July 2008 on seven patients. All patients were intubated and ventilated, receiving enteral feeding and had not had bowel surgery.

- The objectives were to determine how long after admission aperients were given, which aperients were given, and how long after admission patients' bowels were opened.

- Patients were commenced on aperients on day four of admission on average. All patients received prune juice twice daily and then variants of macrogol (Movicol ${ }^{\mathrm{TM}}$ ), lactulose, enema (Microlax ${ }^{\mathrm{TM}}$ ), and senna. On average, bowels were opened on day nine of admission. A need for a bowel care protocol was identified and a protocol was developed between June 2008 and February 2009.

- $\quad$ Education sessions for staff were carried out from March 2009 onwards and the protocol was implemented in July 2009.

- A repeat audit in May-June 2010 was carried out on seven patients. Patients were commenced on the protocol on days one or two of admission on average.

- Bowels were opened on day 5.3 of admission on average. It was clear from the results that the implementation of a formal protocol has improved bowel care and decreased constipation.

\section{INTRODUCTION}

Mater Adult Hospital ICU is an eleven-bed general intensive care unit (ICU) in South Brisbane with approximately 600 admissions per year. The unit is led by five intensivists who are rostered to lead the unit one week at a time.

In 2008, the unit did not have a formal bowel care protocol in place and bowel care was addressed using an unsystematic approach. Aperients were given in various forms and quantities and at different stages of the patient's admission.

A general observation was that constipation appeared to be a problem. The author approached the Nurse Unit Manager regarding whether there was a need to develop a protocol. It was agreed to carry out an audit to determine what action the unit was taking to prevent constipation and to identify any areas of improvement.

\section{IMPLEMENTATION OF THE PROTOCOL}

A five-stage cycle was used as a guide for the audit process and a small audit was carried out on seven patients in June-July 2007. Each of these stages is summarised in the following section. 


\section{Stage 1 - Preparation for audit}

This was the general observation period in which it was idedntified that constipation was a problem.

\section{Stage 2 - Selection of audit criteria}

The inclusion criteria were patients who were intubated and ventilated, receiving enteral feeding and had not had bowel surgery. Although constipation can be a problem for any patient it was decided to concentrate on this small group as it represented the typical ICU patient. Patients post bowel surgery were excluded as they were at high risk of developing an ileus.

\section{Stage 3 - Measuring current practice}

This stage involved looking at how long after admission aperients were given, which aperients were given and how long after admission patients' were bowels opened.

Patients were commenced on aperients on day four of admission on average. All patients received prune juice twice daily and then variants of macrogol (Movicol ${ }^{\mathrm{TM}}$ ), lactulose, enema (Microlax ${ }^{\mathrm{TM}}$ ), and senna. On average, bowels were opened on day nine of admission. The effect of constipation on patients within ICU was reviewed using the literature. It had been documented that constipation is a symptom that is often overlooked and does not receive attention until it is a problem (Ross 1998) and that continence assessment may be a low priority in a nurse's workload (Bayliss \& Salter 2004). Causes of constipation are opioids, diuretics, anticonvulsants, antidepressants and loss of privacy (McKenna et al. 2001) and constipation can prolong both the time to wean from mechanical ventilation and length of ICU stay (Van der Spoel et al. 2006). It was clear from the literature that ICU patients were at risk of developing constipation, and that constipation can have a serious detrimental effect.

The author approached the Nurse Unit Manager and the Clinical Nurse Consultant and a need for a bowel care protocol was identified. A protocol was developed between June 2008 and February 2009. This involved searching the literature to determine best practice and looking at protocols already implemented within other ICUs. The multi-disciplinary team involved in the implementation of the protocol included the author, the clinical nurse consultant, intensivists, a pharmacist, and a dietician (see Picture 1).

\section{Stage 4 - Implementation of change}

Change was implemented from March 2009 onwards by carrying out in-service education sessions for staff. These sessions raised awareness of the effects and risks of constipation with ICU patients and provided education on using the protocol, which was implemented in July 2009.

Amendments in the early months included adding an area for a medical officer to prescribe the protocol. This was because there were examples of patients being placed on the protocol that should have been excluded.

\section{Stage 5 - Re-audit}

A repeat audit was carried in June-July 2010 out on seven patients. The purpose of a re-audit is to ensure that the change implemented in stage four has been successful in improving current practice.

Patients were commenced on the protocol on day 1.6 of admission on average. Bowels were opened on day 5.3 of admission on average. As shown in Figure 1, it was clear from the results of the audit that the implementation of a formal protocol has improved bowel care and decreased constipation.

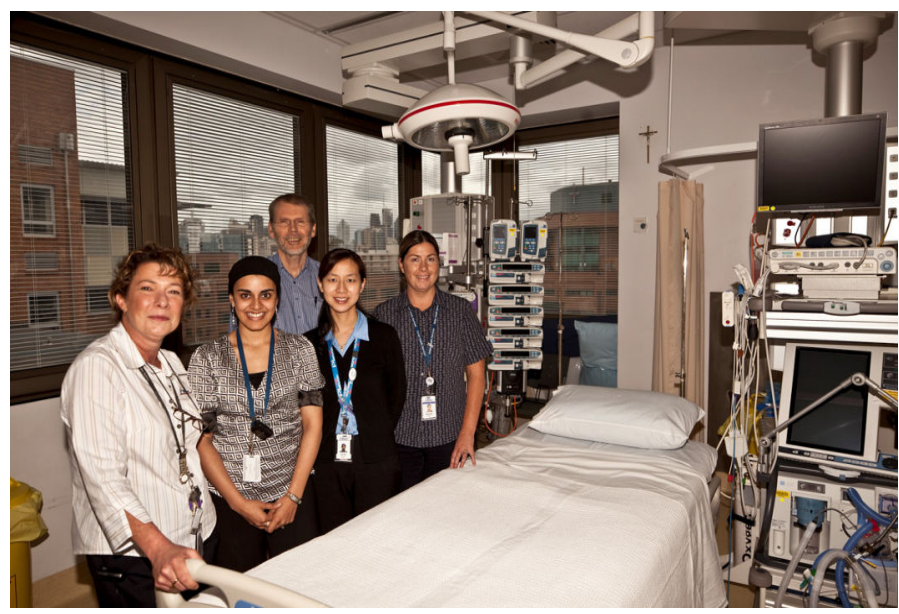

Picture 1. Multi-disciplinary team members (left to right: Anne Conway (Clinical Nurse Consultant), Ra'essa Doolan (dietician), John Morgan (intensivist), Helen Mok (pharmacist), Michelle Ring (Clinical Nurse).

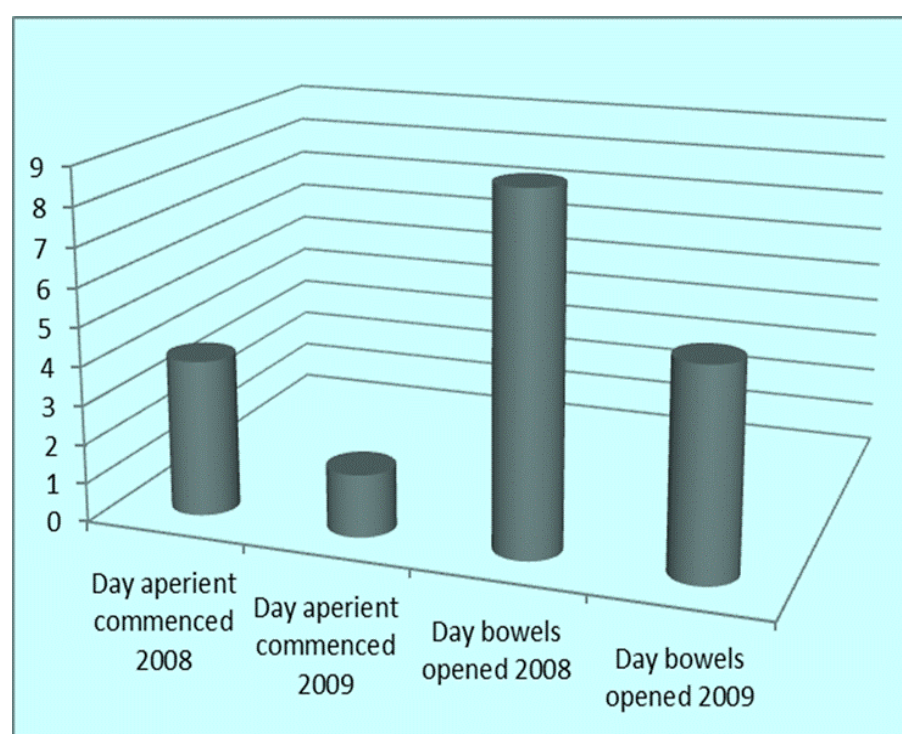

Figure 1. Audit results

\section{THE PROTOCOL}

The protocol (Figure 2) is for use with adult intensive care patients only. The following conditions are applied to its use:

- All patients commenced on enteral feeding to be commenced on bowel protocol unless contra-indicated.

- Protocol to be commenced on ICI medical officer's order.

- Certain patients are excluded from the protocol, for example, those with ileus or post-abdominal (gut) surgery.

- Night staff document on the patient's chart at midnight which day of the protocol the patient is on.

- All bowel activity/inactivity is documented every shift, stating quantity and description, for example, "large, semi-formed" or "small amount, loose, approximately $100 \mathrm{~mL}$."

- Diarrhoea is defined as three or more liquid/unformed stools per day or daily output exceeding $300 \mathrm{~mL}$ 


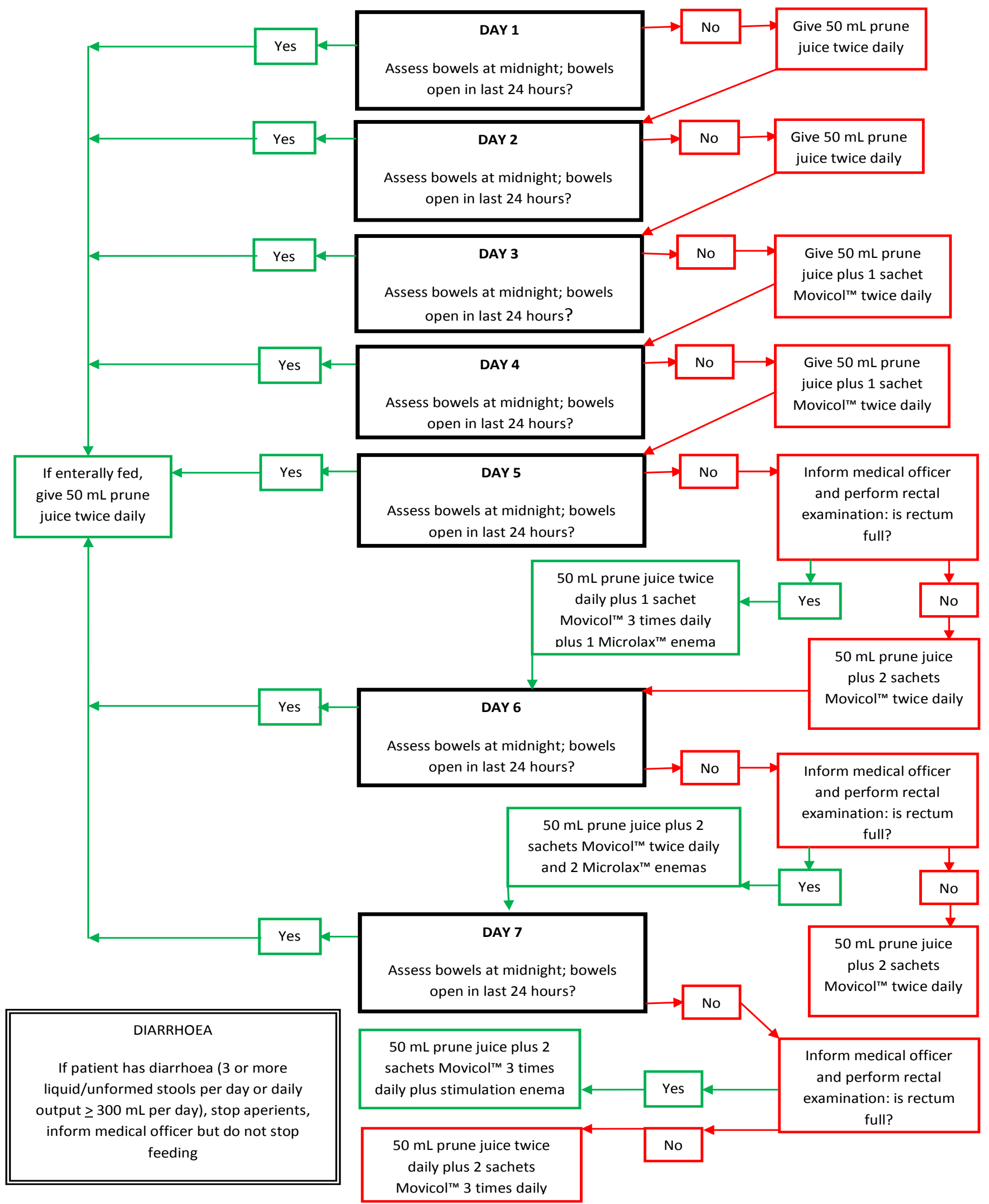

Figure 2. Bowel management protocol 


\section{Diarrhoea management}

If the patient has diarrhoea, the following actions are implemented:

- Stop aperients and document

- Do not automatically stop feeding

- Cause of diarrhoea to be considered and patient to be reviewed by medical officer, dietician, and pharmacist

- Stool specimen collected to check for clostridium difficile

- Rectal examination performed to exclude overflow

- $\quad$ Night staff to assess daily at midnight; when patient has not had bowels open for 24 hours recommence on day 1 of protocol

\section{REFERENCES}

Bayliss V, Salter L (2004). Pathways for evidence based continence care. Nursing Standard 19 (9), 45-51.

McKenna S, Wallis M, Brannelly A, Cawood J (2001). The nursing management of diarrhoea and constipation before and after the implementation of a bowel management protocol. Australian Critical Care 14 (1), 10-16.

Patel S (2010). Achieving quality assurance through clinical audit. Nursing Management-UK 17 (3), 28-35.

Ross H (1998). Constipation: cause and control in a hospital setting. British Journal of Nursing 7 (15), 907-913.

Van der Spoel JI, Schulz MJ, van der Voort PJH (2006). Influence of severity of illness, medication and selective decontamination on defecation. Intensive Care Medicine 32 (6), 875-880. 